network of the intestine. Dr. Beattie demonstrated changes in living lachrymal gland cells during activity. Dr. Irwin found evidence of migration of the 'fixed' cells of the reticuloendothelial system of the liver after the administration of thorium dioxide. Dr. F. G. Banting and his collaborators presented a series of papers on silicosis. It was shown that silica can be absorbed from the intestine and excreted in the urine. Dr. Wylie showed that two injections of 'T.A.B.' vaccine produced maximum agglutinin content. Further injections caused no change in the titre. Prof. Reed found that Ps.-pyocyancus can be separated into several types of colony form not distinguishable by differences in virulence nor by antigenic reactions.

An interesting paper by Prof. A. G. Huntsman on the herring and Archimedean forces in the water explained the migrations of those fish as mainly passive and due to currents, some of which are caused by influx of fresh water into the sea.
The botanical list included a number of phytogeographical studies by Frère Marie-Victorin and his associates. An ecological map of Quebec was shown. In a brief report of their work on the physiology of stomata by Prof. G. Scarth and his associates, it was announced that shortage of oxygen in the leaf causes opening of stomata in the dark. The lumeniferous mycelium and unique gemmæ of Omphalia flavida were described by Prof. A. H. R. Buller. From Prof. R. B. Thomson's laboratories came a careful sytological study of teliospore development in Hyalospora aspilliotus by S. M. Pady, and other mycological and physiological papers as well as further support of Thomson's theory of heterothally in contradistinction to heterospory as a characteristic of seed plants. A number of papers by Prof. C. L. Huskins and his collaborators dealt with the mechanism of reduction of chromosomes, the formation of chiasmata and the origin of meiosis.

\title{
Obituary
}

\section{Dr. E. E. FourNIER D'Albe}

$\mathrm{T}$ HE death occurred on June 29 at his home at St. Albans, Hertfordshire, at the age of sixty-five years, of Dr. Edmund Edward Fournier d'Albe.

Dr. Fournier d'Albe was known for his work on the properties of selenium. In a paper published in the Proceedings of the Royal Society in 1912, he gave the results of his work on the dependence of the electrical conductivity of selenium on voltage. He showed that the 'potential effect' $\left(R_{0}-R_{v}\right) / R_{0}$ (where $R_{0}$ is the resistance at infinitesimal voltage and $R_{v}$ the resistance at voltage $v$ ) is proportional to the logarithm of the voltage. A later paper (Proc. Roy. Soc., 89, 75; 1913) dealt with the efficiency of selenium as a detector of light. The experiments described show that a selenium 'bridge' is far more sensitive than the human eye, being able to detect illumination of the order of $10^{-5}$ metre candle. These experiments also led him to the conclusion that the change of resistance is proportional to the square root of the illumination. Struck by this sensitiveness, he made an unsuccessful attempt to demonstrate the discontinuity of the wave front of light.

The practical application of the properties of selenium was ever before Dr. Fournier d'Albe and he devised an ingenious instrument, which he named the "Optophone", by means of which it was possible by moving an aperture over a line of printed type to produce sounds in a telephone, each letter giving a characteristic sequence of musical chords. In this way it was shown to be possible for a blind person to recognise the various letters by their sounds, and so to read the type by ear. The instrument was described in the Proceedings of the Royal Society $(90,373 ; 1914) . \quad$ The idea was developed commercially but the costliness of the apparatus was a serious obstacle to its use as a means of mitigating the disabilities of the sightless, and he spent many years in his attempts to overcome this limitation.

Dr. Fournier d'Albe also made early experiments on television with some success.

It was announced on July 14 that Dr. Fournier d'Albe had been granted a Civil List pension of $£ 125$ a year "in recognition of his contributions to the science of physics and his invention of the optophone and other scientific appliances".

$$
\text { G. A. S. }
$$

Dr. E. E. Fournier D'Albe began his contributions to scientific journalism by supplying abstracts of scientific publications to the Electrician in about 1893. These developed into a weekly column under the title "Contemporary Electrical Science" from 1897 until 1905. The "Science Abstracts" of the Physical Society began in 1895, and after forty years of such work the initials "E.E.F.d'A." appeared regularly until the number issued for last month. In April last he wrote: "I live in retirement since a 'stroke' six years ago deprived me of my right hand. Nevertheless, I am otherwise in perfect health, and typewrite my own letters and literary work. . . . I amuse myself with photoelectric astronomy and riding about the country on an invalid motor tricycle".

In December 1895 Dr. Fournier d'Albe wrote an article on "The Classification of Physical Experiments" (Electrician, 36, 781). His object was to specify and to suggest a classification and notation for the broad types of experimental work in physics by means of symbols capable of international use, and the discovery of gaps in the series which remained yet to be filled up. His system showed ingenuity and a tidy mind, but 